\title{
ECO-EFICIÊNCIA NO PROJETO DE CIRCUITOS DE COMINUIÇÃO: O CASO BRASILEIRO*
}

Juliana Segura Salazar ${ }^{1}$ Luís Marcelo Tavares ${ }^{2}$

\section{Resumo}

Algumas estratégias vêm sendo incorporadas na cominuição de minérios, voltadas para reduzir os custos operacionais (OPEX) e garantir o funcionamento de suas operações no longo prazo. Paralelamente, elas permitem reduzir os impactos ambientais desta operação sob a ótica da sustentabilidade, devido às melhorias na eficiência de uso dos recursos e na mitigação das mudanças climáticas. Porém, a incorporação dessas estratégias é restrita pelo tipo de tecnologia empregada e pelo layout da usina e, portanto, o maior potencial de minimização dos impactos econômicos e ambientais encontra-se principalmente na etapa de projeto dos circuitos. Este potencial muitas vezes é desperdiçado, sendo ainda poucas as implementações sistemáticas adotadas na indústria mineral, visando melhorar a ecoeficiência dos processos. Neste trabalho é proposta uma metodologia fundamentada em princípios de sustentabilidade e aplicável ao beneficiamento de minérios, usando uma abordagem simplificada da Avaliação de Ciclo de Vida (ACV). A metodologia é focada na cominuição de minérios brasileiros, tendo sido aplicada ao beneficiamento de Itabiritos, os quais estão se tornando estratégicos no Brasil.

Palavras-chave: Eco-eficiência; Cominuição; Simulação de processos; Itabiritos.

\section{ECO-EFFICIENCY IN THE DESIGN OF COMMINUTION CIRCUITS: THE BRAZILIAN CASE STUDY}

\section{Abstract}

A number of strategies are being incorporated in the comminution of ores in order to ensure the functioning of its operations in the long term, mainly focused on reducing operating costs (OPEX). In addition, these strategies support the minimization of environmental impacts in comminution operations from the sustainability standpoint, due to improvements in the resource use efficiency, as well as in climate change mitigation. However, the adoption of these principles is restricted by the type of technology used and by the plant layout. Therefore, the greatest opportunity in minimizing these economic and environmental impacts is primarily in the plant design stage. In spite of this potential, only a few experiences and systematic implementations based on eco-efficiency principles have been undertaken in the minerals industry. The present paper proposes a methodology based on sustainability principles applied to beneficiation operations, using a simplified Life Cycle Assessment (LCA) approach. The proposed methodology has emphasis on comminution of Brazilian ores, having been applied to itabirite iron ores, whose beneficiation is becoming strategic for current and future projects in Brazil.

Keywords: Eco-efficiency; Comminution; Process simulation; Itabirite ore.

1 Eng. Química, M.Sc. em Eng. Metalúrgica e de Materiais, Estudante de Doutorado, Departamento de Engenharia Metalúrgica e de Materiais, Laboratório de Tecnologia Mineral, Universidade Federal do Rio de Janeiro, Rio de Janeiro, Brasil.

2 Eng. de Minas, Ph.D em Engenharia Metalúrgica, Professor Titular, Departamento de Engenharia Metalúrgica e de Materiais, Laboratório de Tecnologia Mineral, Universidade Federal do Rio de Janeiro, Rio de Janeiro, Brasil. 


\section{INTRODUÇÃO}

A definição clássica de sustentabilidade tem sido estabelecida com base na interação - comumente referida como Triple Bottom Line - entre três componentes principais: meio ambiente, economia e sociedade, sendo a interação das últimas duas conhecidas como Eco-eficiência [1]. No contexto da mineração, Laurence [2] considera que aquela definição precisa ser repensada, com o intuito de incluir outras duas importantes dimensões que estão sendo mal abordadas. A primeira está relacionada com o cumprimento de elevados padrões de segurança, por meio da incorporação de boas práticas de segurança, de adequados sistemas de comunicação, de treinamento e de educação dentro da companhia. A segunda dimensão refere-se à mineração eficiente do recurso, por exemplo, estender a vida útil da mina por meio do aproveitamento de minérios de baixo teor e não apenas daqueles de alto teor. Todas essas componentes, em conjunto, poderão contribuir não somente para estender o tempo de operação da mina, mas também para reduzir os impactos decorrentes da atividade extrativa.

Apesar do enorme potencial de melhoria na sustentabilidade das operações de processamento de minérios, tem sido desenvolvido apenas um número limitado de estudos sistemáticos baseados em princípios de sustentabilidade. Além disso, a incorporação de práticas de sustentabilidade no nível corporativo, apesar de ter sido significativa, tem encontrado uma persistente dificuldade de integração no âmbito operacional. Uma estratégia que pode contribuir significativamente para a adoção sistemática daqueles princípios de sustentabilidade em empresas do setor mineral é a definição de indicadores apropriados para quantificar os impactos das operações de maneira objetiva e prática [3]. Têm sido propostas diferentes metodologias para a análise dos impactos de uma operação, produto ou serviço, sendo a Avaliação do Ciclo de Vida (ACV) uma das metodologias mais promissoras na área de processamento mineral [4,5]. Neste trabalho são analisados e discutidos alguns aspectos relevantes relacionados com a sustentabilidade em operações de processamento de minérios, com particular ênfase na ferramenta de ACV integrada à análise de processos de cominuição, por meio de uma abordagem simplificada baseada em estudos prévios. A metodologia proposta tem sido aplicada com sucesso na comparação de circuitos de cominuição que foram projetados para um minério de ferro de baixo teor, cujo aproveitamento está se tornando estratégico nos projetos atuais e futuros do setor mineiro no Brasil.

\section{ADOÇÃO DE PRÁTICAS SUSTENTÁVEIS NO PROCESSAMENTO DE MINÉRIOS: UMA VISÃO HOLÍSTICA}

Um dos paradigmas que precisa ser quebrado no setor mineral em alguns países é a ideia da incompatibilidade desta atividade econômica com o desenvolvimento sustentável, devido ao evidente esgotamento dos recursos minerais que, inevitavelmente, deverá ocorrer em qualquer mina. Essa confusão decorre, segundo Batterham [6], de uma inadequada interpretação da sustentabilidade, na qual é presumido que os recursos são inesgotáveis. Assim, a sustentabilidade na indústria extrativa mineral não deve ser referida apenas ao licenciamento de uma mina cujo recurso não seja facilmente inesgotável: trata-se de entender a natureza global do recurso e, sobretudo, de adotar princípios de sustentabilidade na operação de qualquer mina, tanto em pequena escala - mineração artesanal - como em escala industrial. No âmbito da eco-eficiência, é fundamental entender a natureza dos 
impactos ambientais do setor mineral, os quais, por sua vez, podem ter maior ou menor intensidade em função de outros fatores como a localização geográfica, como veremos mais adiante.

\subsection{Gases de Efeito Estufa e Mecanismos de Redução de Emissões}

De acordo com o grupo de pesquisadores do Intergovernmental Panel on Climate Change (IPCC), o principal fator que contribui no aumento das emissões de Gases de Efeito Estufa (GEE) é a queima de combustíveis fósseis tanto na geração de energia quanto na fabricação de bens de consumo. Na indústria minero-metalúrgica essas emissões $\left(\mathrm{CO}_{2}\right.$ como o principal gás emitido) se encontram associadas principalmente à demanda de energia em cada estágio da cadeia produtiva, desde a exploração e mineração até a produção do metal refinado. A energia elétrica empregada nessas operações procede de diversas fontes - renováveis e não renováveis - que devem ser identificadas para cada área produtiva, a fim de obter uma estimativa adequada das emissões de GEE. As emissões, por sua vez, devem ser ajustadas considerando a eficiência térmica da central elétrica além das perdas energéticas durante a transmissão desde o gerador até a localização das instalações produtivas [7].

Têm sido criados alguns mecanismos como o Comércio de Emissões, com o intuito de estimular a redução das emissões de GEE, em decorrência dos compromissos assumidos pelos países signatários do Protocolo de Quioto, bem como do interesse de outros países-regiões-setores industriais em se aderir a esta iniciativa e contribuir voluntariamente na meta global de mitigação das mudanças climáticas. Segundo um recente relatório do Banco Mundial [8], mais de 40 países e 20 jurisdições subnacionais têm incorporado ou estão em processo de considerar a precificação do carbono. O Brasil se encontra nesta última categoria, sendo atualmente um tema de debate público o estabelecimento de um esquema de precificação de carbono, fundamentado na Política Nacional sobre a Mudança do Clima (PNMC).

\subsection{Emissões de $\mathrm{CO}_{2}$ e Consumo Energético Global}

Como mencionado acima, as emissões de $\mathrm{CO}_{2}$ associadas ao consumo de eletricidade - energia direta - em usinas de beneficiamento de minérios dependem da fonte energética empregada. O Brasil tem lugar de destaque no contexto internacional por possuir uma matriz energética limpa, ou seja, com uma alta participação de fontes renováveis, quando comparado com a média mundial, especialmente no setor de eletricidade [9]. Isso resulta em uma importante diferença entre as emissões brasileiras de $\mathrm{CO}_{2}$ equivalente por unidade de energia respeito àquelas de outros países, em particular da Austrália, onde tem sido realizada a maior quantidade de estudos neste âmbito. Este fato torna-se mais evidente quando é analisada a Tabela 1, onde são comparados os fatores de emissão de $\mathrm{CO}_{2}$ associados ao consumo de eletricidade que foram empregados em uma série de estudos de caso da indústria mineral. É claro que o fator de emissão associado à eletricidade depende fortemente do tipo de fonte energética empregada e também da localização da operação. Ainda mais, são encontradas diferenças significativas na matriz energética entre diferentes estados ou regiões de um país, como pode ser observado no trabalho de Memary et al. [10]. 
Tabela 1. Fatores de emissão de $\mathrm{CO}_{2}$ para o consumo de eletricidade em diferentes estudos de caso da indústria mineral

\begin{tabular}{|c|c|c|c|}
\hline Estudo de Caso & Comentário & $\begin{array}{l}\text { Fator de emissão de } \mathrm{CO}_{2} \text { eq. } \\
(\mathrm{t} / \mathrm{MWh})\end{array}$ & Referência \\
\hline $\begin{array}{l}\text { Processamento } \\
\text { de minério de } \\
\text { ferro (Magnetita) }\end{array}$ & $\begin{array}{c}\text { Operação } \\
\text { localizada na } \\
\text { Austrália }\end{array}$ & 1 & $\begin{array}{c}\text { McNab et al. } \\
{[11]}\end{array}$ \\
\hline $\begin{array}{l}\text { Circuitos de } \\
\text { cominuição } \\
\text { baseados em } \\
\text { uma operação de } \\
\text { cobre-ouro } \\
\end{array}$ & $\begin{array}{l}\text { Diferentes fontes } \\
\text { energéticas } \\
\text { usando base de } \\
\text { dados australiana }\end{array}$ & $\begin{array}{c}\text { 0,997 (carvão mineral) } \\
\text { 0,596 (gás natural) } \\
0,528 \text { (diesel) } \\
0 \text { (renováveis) }\end{array}$ & $\begin{array}{l}\text { Pokrajcic, } \\
\text { O'Halloran, e } \\
\text { Jones [12] }\end{array}$ \\
\hline $\begin{array}{l}\text { Processos de } \\
\text { produção de } \\
\text { metais primários }\end{array}$ & $\begin{array}{l}\text { Estudo usando } \\
\text { base de dados } \\
\text { australiana }\end{array}$ & $\begin{array}{c}0,962 \text { (principalmente carvão } \\
\text { mineral) }\end{array}$ & $\begin{array}{c}\text { Norgate e } \\
\text { Jahanshahi } \\
\text { [13] }\end{array}$ \\
\hline $\begin{array}{l}\text { Processos de } \\
\text { mineração e } \\
\text { fundição em } \\
\text { minas de cobre } \\
\text { no período } 1940 \\
-2008 \\
\end{array}$ & $\begin{array}{l}\text { Cinco das maiores } \\
\text { minas australianas } \\
\text { de cobre }(60 \% \text { da } \\
\text { produção nacional }) \\
\text { e diferentes fontes } \\
\text { energéticas } \\
\end{array}$ & $\begin{array}{c}0,01-0,24 \text { (rede elétrica do } \\
\text { Estado de Tasmânia) } \\
0,89-1,09 \text { (rede elétrica do } \\
\text { Estado de Austrália do Sul) } \\
0,358 \text { (principalmente gás } \\
\text { natural) } \\
\end{array}$ & $\begin{array}{l}\text { Memary et } \\
\text { al.[10] }\end{array}$ \\
\hline $\begin{array}{l}\text { Cominuição de } \\
\text { minério de ferro } \\
\text { (Itabirito) }\end{array}$ & $\begin{array}{c}\text { Operação } \\
\text { localizada no Brasil }\end{array}$ & $\begin{array}{c}0,0653 \\
\text { (principalmente } \\
\text { hidroeletricidade) }\end{array}$ & $\begin{array}{l}\text { Segura e } \\
\text { Tavares [9] }\end{array}$ \\
\hline
\end{tabular}

Assim, existem fatores chave que devem ser considerados do ponto de vista da ecoeficiência, especialmente durante o projeto de uma nova usina. Nesse sentido, podese pensar que a indústria mineral brasileira faz uma diferença significativa em termos de impactos ambientais das operações quando comparada com indústrias semelhantes que operam em países como a China ou a Austrália onde, até hoje, os combustíveis fósseis continuam a ser uma importante fonte energética. No entanto, outros fatores devem ser considerados para fins comparativos, tais como o teor e a complexidade dos minérios e o tipo de tecnologias adotadas.

Por outro lado, há também um consumo de energia indireto em cada uma das etapas do ciclo de vida de uma operação de processamento mineral. Na cominuição de minérios, esse consumo corresponde fundamentalmente à energia demandada para fabricar os materiais de desgaste necessários em equipamentos de cominuição, entre eles os corpos moedores e revestimentos de britadores e moinhos, compostos principalmente de aço e ligas ferrosas. Segundo Henriques Jr [14], a produção de aço baseada nas tecnologias mais avançadas pode reduzir o consumo de energia específica a $4,1 \mathrm{kWh}$ por kg de aço. Rankin [15] menciona que existe um limite teórico na possibilidade de redução do consumo energético demandado na produção de metais devido a restrições termodinâmicas, e que os atuais processos de fabricação de aço se encontram longe deste limite. Considerando o fato que o minério de ferro de alto teor está se tornando escasso, a energia embutida no processo de fabricação de aço pode aumentar no futuro, uma vez que seriam necessários estágios consumidores de energia adicionais e mais minério precisaria ser extraído e processado por unidade de aço produzida, apesar da possibilidade de incorporar tecnologias energeticamente mais eficientes nos próximos anos.

No que diz respeito às emissões de GEE associadas ao consumo energético indireto, tem sido observado [9] que o fator de emissão médio brasileiro (em 
toneladas de $\mathrm{CO}_{2}$ equivalente por tonelada de aço) é levemente inferior [16] comparado com o valor médio reportado na base de dados da World Steel Association. Essa diferença pode ser atribuída a diferentes fatores, entre eles a utilização de carvão vegetal em rotas integradas, o uso de materiais reciclados em rotas semi-integradas, o reaproveitamento de gases de processo, o uso de finos de carvão e a substituição de óleo combustível por gás natural [16, 17]. No entanto, de acordo com a Confederação Nacional da Indústria e o Instituto Aço Brasil, não é técnica nem economicamente viável no Brasil a substituição da produção total de aço via rota integrada pela rota semi-integrada, nem a substituição do carvão mineral total empregado na rota integrada pelo carvão vegetal [17]. Além disso, existe um importante desafio no setor siderúrgico brasileiro no que diz respeito à mitigação das mudanças climáticas, pois uma boa parte do carvão vegetal empregado é obtida por meio do desmatamento da floresta nativa [18].

\section{A FERRAMENTA DE AVALIAÇÃO DO CICLO DE VIDA (ACV) E SUA APLICAÇÃO EM PROCESSOS DE COMINUIÇÃO}

A ferramenta de ACV tem sido aplicada com bastante sucesso na estimação dos impactos ambientais de diferentes setores industriais. Esta metodologia, baseada na série de normas ISO 14000, permite a elaboração de um inventário de entradas e saídas para um determinado sistema previamente selecionado (produto ou operação) em cada fase do ciclo de vida, bem como a identificação de impactos ambientais potenciais associados a cada uma dessas categorias do inventário e que podem ser quantificados por meio de diferentes indicadores (Figura 1).

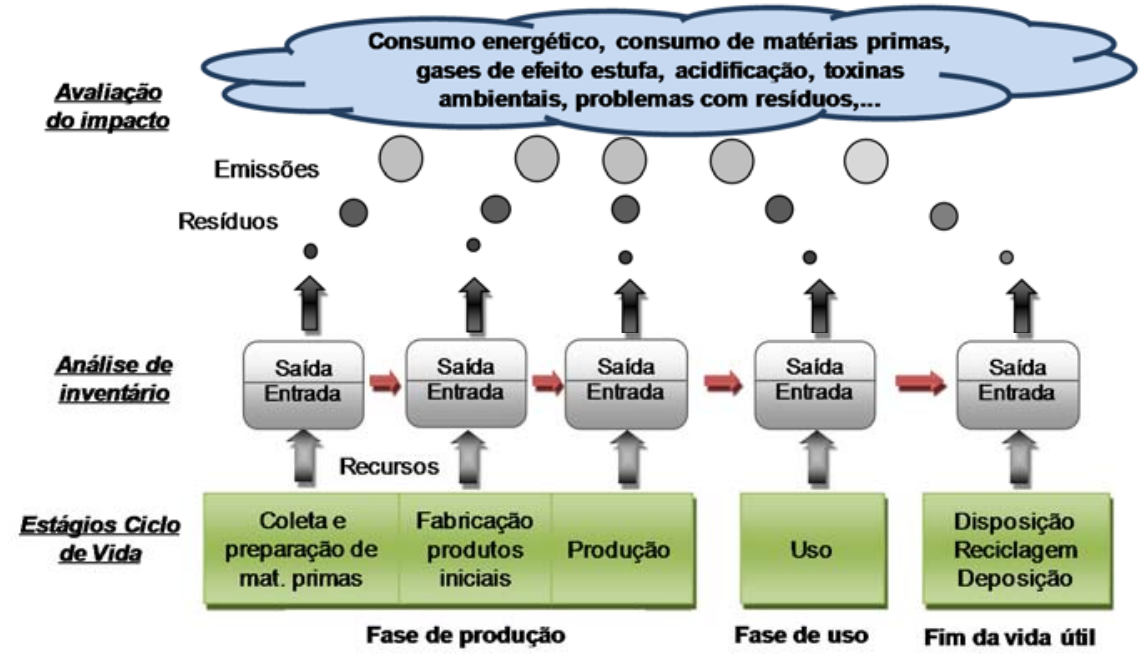

Figura 1. Estrutura de ACV (Adaptado de: Caldeira-Pires [19])

Um dos primeiros estudos referentes à aplicação de ACV nos processos de cominuição foi desenvolvido no ano 2000 por Landfield e Karra [20]. Neste trabalho, o fabricante de britadores Nordberg aplicou a ferramenta de ACV a um dos seus produtos, com o intuito de identificar oportunidades para seu melhoramento em termos de projeto e eficiência energética. Os autores analisaram cada uma das fases do ciclo de vida do britador e concluíram que a etapa com maiores impactos ambientais em termos de consumo de matérias primas e de emissões de GEE correspondeu ao uso do britador, com $94 \%$ das contribuições totais em consumo de aço (associado à substituição de materiais de desgaste) e $99 \%$ ou mais das contribuições totais às emissões de GEE e ao consumo de eletricidade. 
Quase uma década depois, Musa e Morrison [21] propuseram uma metodologia para a avaliação da eco-eficiência energética dos processos de cominuição, por meio da estimação dos consumos energéticos direto e indireto no processo. Esta abordagem também foi baseada na ferramenta de ACV e a maioria das informações concernentes ao consumo de eletricidade e materiais de desgaste foi coletada a partir de medições em amostragens industriais e também da base de dados histórica da operação da usina. Adicionalmente, neste estudo, as categorias de impacto restringiram-se à demanda energética y à emissão de GEE. Esta metodologia demonstrou ser muito útil para comparar diferentes rotas de cominuição em termos de impactos ambientais, os quais, pela sua vez, se encontram relacionados aos aspectos econômicos.

O estudo realizado por Norgate e Jahanshahi [13] revelou que a cominuição pode contribuir na redução dos impactos ambientais do processamento de minérios, por meio da melhora na eficiência energética de moinhos e britadores. Os autores argumentaram que a energia de cominuição global necessária para a produção de dos principais minerais metálicos, projetada até 2030, será de aproximadamente quatro vezes o consumo atual. Os principais fatores que incidem nesse incremento da demanda energética são a tendência de diminuição no teor dos minérios nos próximos anos, o incremento na complexidade das novas jazidas e, consequentemente, a necessidade de moer até tamanhos mais finos para atingir a liberação desejada do componente de interesse. Este novo cenário resultaria, por sua vez, em um incremento nas emissões de GEE, seja pelo contínuo emprego de fontes energéticas não renováveis ou pela crescente demanda de materiais de desgaste nos processos de cominuição. Os estudos acima citados evidenciaram a importância de incorporar uma nova linha de pensamento nas operações de cominuição. Surge então a questão do que pode ser feito para adotar este tipo de metodologia quando os dados operacionais são limitados ou indisponíveis, como no caso da etapa de concepção de um novo projeto. Isto será analisado na próxima seção.

\subsection{Uma Abordagem Simplificada baseada na ACV e Aplicada à Cominuição de Minérios}

Recentemente, tem sido proposta uma metodologia simplificada baseada na ferramenta de ACV [22], a fim de estabelecer os potenciais impactos ambientais das operações de cominuição. A metodologia foi desenvolvida visando lidar com o caso no qual as informações concernentes à operação do processo não se encontram disponíveis, ou seja, na fase de projeto de uma usina. Portanto, nesta etapa apenas existem informações concernentes à caracterização do minério, ensaios de bancada e piloto, além de informações básicas e critérios de projeto para o minério em estudo.

Foram incorporadas ferramentas adicionais de análise (Figura 2), a fim de comparar as diferentes rotas potenciais de cominuição. A abordagem consiste basicamente de uma etapa inicial na qual, com base na informação coletada, são simuladas cada uma das rotas de processamento previamente estabelecidas. Com esses resultados e com algumas estimativas de taxa de desgaste em revestimentos e corpos moedores, de fatores de emissão de $\mathrm{CO}_{2}$ (associados ao consumo de eletricidade e à produção de materiais de desgaste) e de fatores de consumo específico de energia para a produção de materiais de desgaste, é possível desenvolver um Inventário de Ciclo de Vida (ICV) em cada um dos sistemas selecionados. Os 
resultados deste inventário - em termos de entradas e saídas do processo - são normalizados com base em uma unidade funcional (por exemplo, em relação à taxa de alimentação de minério ao circuito) e, consequentemente, podem ser considerados como indicadores de desempenho para cada rota de processamento.

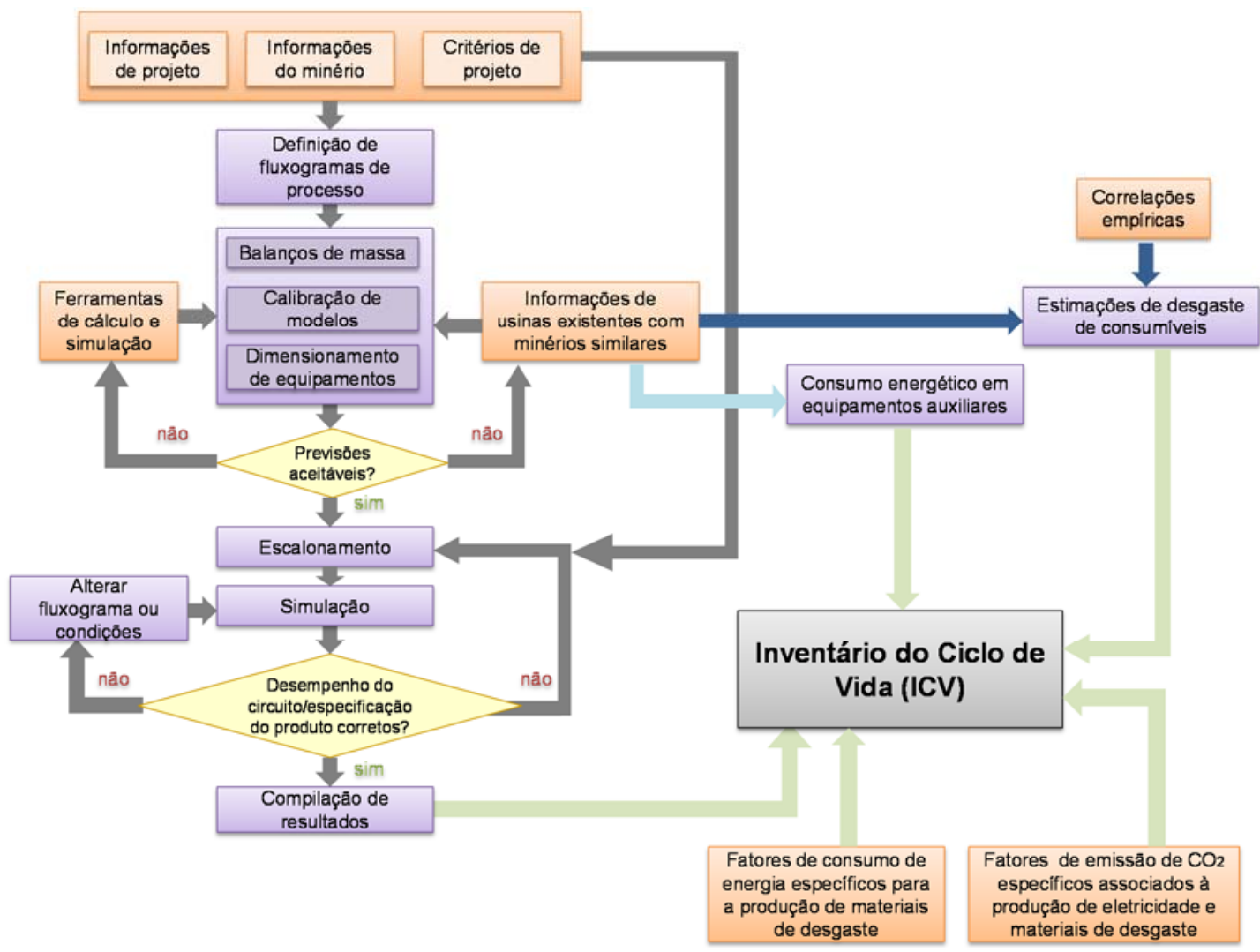

Figura 2. Abordagem baseada em ACV aplicada ao projeto de processos de cominuição

A metodologia proposta tem sido focada na fase de uso do ciclo de vida dos equipamentos de cominuição (Figura 1), assumindo que ela representa o maior impacto no ciclo de vida dos processos de cominuição, com base em resultados de estudos prévios [20]. Esta abordagem é equivalente a considerar a fase de produção do ciclo de vida do minério concentrado, ou seja, é realizada uma ACV parcial gateto-gate, simplificação que resulta conveniente para fins práticos e sob a ótica do projeto de rotas de processamento de minérios mais eco-eficientes.

\subsection{Estudo de Caso: Projeto de um Circuito de Cominuição para um Minério de Ferro Itabirítico}

Tem sido estabelecido que a cominuição representa a etapa de maior consumo energético em operações de mineração e processamento de minérios, demandando quase $70 \%$ da energia elétrica [13]. Aliás, estimativas recentes [4] sugerem que a cominuição, em geral, consome aproximadamente $1,8 \%$ da energia elétrica gerada no mundo. Conforme mencionado acima, este consumo não se encontra apenas relacionado à potência fornecida aos britadores, moinhos ou a qualquer outro equipamento de um processo de cominuição (incluindo operações de classificação e transporte de material entre estágios), mas também à energia 'embutida' ou indireta, principalmente associada àqueles materiais de desgaste (revestimentos e corpos moedores) que são continuamente demandados durante a operação. 
A cominuição de minérios de ferro de baixo teor - itabiritos - está se tornando estratégica no setor mineral brasileiro, como tem sido observado no recente início de operação de usinas de beneficiamento destes minérios. Exemplos dessas operações envolvem o projeto Minas-Rio da Anglo Ferrous Brasil e o projeto Conceição da Vale S.A., entre vários outros que ainda se encontram em fase de projeto ou de implementação, todos eles localizados no Estado de Minas Gerais. As particularidades dos itabiritos em relação aos minérios de ferro de alto teor hematitas - fazem com que o beneficiamento dos primeiros seja mais desafiante do ponto de vista da demanda energética - direta e indireta - que implica em uma maior taxa de emissões de GEE. Neste contexto, torna-se pertinente uma análise apropriada de rotas de processamento alternativas na indústria de mineração de ferro do Brasil, visando uma maior eco-eficiência.

Em uma recente publicação de Segura e Tavares [9], são comparadas quatro rotas de cominuição para um minério de ferro itabirítico da Vale S.A. Neste estudo de caso, a informação foi coletada a partir de ensaios de caracterização do minério e de ensaios de moagem em batelada e piloto com amostras do Run of Mine (ROM) de depósitos localizados na região do Quadrilátero Ferrífero em Minas Gerais. Com base em critérios de projeto da operação em questão, foi selecionada uma vazão mássica nominal de $3.235 \mathrm{t} / \mathrm{h}$ de minério seco alimentando cada uma das rotas de cominuição a serem projetadas, sendo este material o produto da etapa de britagem primária, cuja distribuição granulométrica encontra-se abaixo de $250 \mathrm{~mm}$ e apresenta uma enorme proporção de partículas finas (aproximadamente 40\% passante em 0,150 mm). As rotas de cominuição propostas foram baseadas em uma extensa revisão de literatura, bem como nas propriedades do minério, descritas a seguir:

I. Britagem convencional em quatro etapas usando britadores cônicos, e duas etapas de moagem em moinhos de bolas. Atualmente esta rota é considerada o processo "padrão", tendo sido baseada na rota de cominuição selecionada pela Vale S.A. para a usina em questão e em usinas em operação da Samarco S.A.

II. HPGR em circuito fechado com alimentação natural como etapa de britagem terciária após uma etapa de britagem secundária em britador cônico, seguida por uma etapa de moagem em moinho de bolas. Esta rota é semelhante ao fluxograma usado no projeto Minas Rio da Anglo Ferrous Brasil.

III. Rota quase idêntica à alternativa III, com a diferença que a alimentação ao HPGR é escalpada.

IV. Circuito SAB (Moinho Semi-autógeno e moagem em moinho de bolas).

Com as informações disponíveis do projeto foi criada uma base de dados que, acoplada ao uso de dois simuladores de processamento mineral (JKSimMet ${ }^{\circledR}$ e MolyCop Tools ${ }^{\circledR}$ ), permitiu otimizar o desempenho de cada uma das rotas de processo propostas (Figura 2). Além dos balanços de massa e dos consumos energéticos dos equipamentos de cominuição, ambos fornecidos pelas simulações, foi necessário estimar o consumo de materiais de desgaste nos equipamentos de cominuição. Isto foi realizado por meio de correlações empíricas e também com base em informações adicionais de um minério com características semelhantes. Com o intuito de comparar as alternativas propostas em termos de indicadores de sustentabilidade, foram estimadas diferentes entradas (energia direta e indireta, aço, água) e saídas (emissões de $\mathrm{CO}_{2}$, material ultrafino) nos sistemas selecionados (cada rota de cominuição), as quais foram normalizadas em relação à taxa de alimentação nominal dos circuitos. 
Usando a metodologia proposta (Figura 2), o estudo revelou que é possível reduzir os impactos ambientais das operações de cominuição não somente pela adoção de tecnologias mais eficientes em termos de minimização de recursos, mas também pelo uso de layouts apropriados, o que está fortemente relacionado com as propriedades do minério em questão. A partir dos resultados do estudo, que são sumarizados na Tabela 2 e analisados em maior detalhe em outra publicação [9], foi concluído que, se fossem incorporados critérios de sustentabilidade na seleção de rotas de cominuição de minérios, a alternativa III - britagem secundária convencional acoplada a HPGR com alimentação escalpada e moagem de bolas seria a mais eficiente em termos de redução de consumo energético direto e indireto e de emissões de $\mathrm{CO}_{2}$. Adicionalmente, tem sido sugerido que a etapa de moagem em moinhos de bolas pode ser potencialmente melhorada por meio do uso de tecnologias mais eco-eficientes que permitam um melhor aproveitamento da potência fornecida ao equipamento de cominuição, bem como uma redução no consumo de outros recursos importantes como a água e os materiais de desgaste (aço), e também com uma menor geração de material ultrafino no produto.

Foi observado que, na maioria das rotas de cominuição propostas (excetuando a alternativa II), a proporção de emissões de $\mathrm{CO}_{2}$ associada a ambas as energias direta e indireta foi semelhante, embora a mesma proporção não seja mantida no caso do consumo energético específico direto e indireto. Isto pode estar relacionado ao fato de que no Brasil existe uma matriz energética relativamente limpa, quando comparada com aquela de outros países como a Austrália (Tabela 1). Portanto, para o caso particular do Brasil, a energia embutida na cominuição - que geralmente não é inventariada - exerce uma importante influência nos impactos ambientais causados por esta operação, principalmente no concernente às emissões de GEE.

O estudo também permitiu concluir que a tecnologia SAG não foi particularmente atrativa sob a ótica da sustentabilidade, mas poderia potencialmente melhorar seu desempenho ambiental se sua variante, a moagem autógena (AG) é viabilizada, mas esta questão se encontra fora do escopo do trabalho. Também existe uma potencial melhora nas etapas de classificação, com a possibilidade de incrementar a capacidade do circuito inteiro e também a recuperação do componente de interesse (ferro), questão que também esteve fora do escopo. É importante reconhecer que a abrangência deste estudo de caso pode ser estendida, a fim de incluir outros indicadores que permitam um entendimento mais compreensivo dos impactos das operações de mineração e de processamento de minérios em cada uma das dimensões da sustentabilidade e suas respectivas interações.

Tabela 2. Inventário do Ciclo de Vida (ICV) para potenciais rotas de cominuição de itabiritos

\begin{tabular}{|c|c|c|c|c|c|c|}
\hline \multirow{6}{*}{ Entrada } & Indicador de ICV & Unidades & Alt. I & Alt. II & Alt. III & Alt. IV \\
\hline & Energia Direta (ED) & $\begin{array}{c}\mathrm{kWh} / \mathrm{t} \\
(\%)\end{array}$ & $\begin{array}{c}3,73 \\
(79,0)\end{array}$ & $\begin{array}{c}4,18 \\
(85,8)\end{array}$ & $\begin{array}{c}3,04 \\
(81,5)\end{array}$ & $\begin{array}{c}3,65 \\
(75,0)\end{array}$ \\
\hline & Energia Indireta (EI) & $\begin{array}{c}\mathrm{kWh} / \mathrm{t} \\
(\%)\end{array}$ & $\begin{array}{c}0,99 \\
(21,0)\end{array}$ & $\begin{array}{c}0,69 \\
(14,2)\end{array}$ & $\begin{array}{c}0,69 \\
(18,5)\end{array}$ & $\begin{array}{c}1,22 \\
(25,0)\end{array}$ \\
\hline & ENERGIA TOTAL & $\mathrm{kWh} / \mathrm{t}$ & 4,72 & 4,88 & 3,73 & 4,87 \\
\hline & Aço & $\mathrm{kg} / \mathrm{t}$ & 0,15 & 0,10 & 0,10 & 0,18 \\
\hline & Água & $\mathrm{t} / \mathrm{t}$ & 2,20 & 2,34 & 2,32 & 1,94 \\
\hline \multirow[t]{4}{*}{ Saída } & Material Ultrafino & $t / t$ & 0,18 & 0,23 & 0,20 & 0,17 \\
\hline & $\begin{array}{c}\text { Emissões de } \mathrm{CO}_{2} \text { Associadas } \\
\text { à ED }\end{array}$ & $\begin{array}{l}\mathrm{kg} / \mathrm{t} \\
(\%)\end{array}$ & $\begin{array}{c}0,24 \\
(51,3)\end{array}$ & $\begin{array}{c}0,27 \\
(63,4)\end{array}$ & $\begin{array}{c}0,20 \\
(55,6)\end{array}$ & $\begin{array}{c}0,24 \\
(45,6)\end{array}$ \\
\hline & $\begin{array}{c}\text { Emissões de } \mathrm{CO}_{2} \text { Associadas } \\
\text { à El }\end{array}$ & $\begin{array}{l}\mathrm{kg} / \mathrm{t} \\
(\%)\end{array}$ & $\begin{array}{c}0,23 \\
(48,7)\end{array}$ & $\begin{array}{c}0,16 \\
(36,6)\end{array}$ & $\begin{array}{c}0,16 \\
(44,4)\end{array}$ & $\begin{array}{c}0,28 \\
(54,4)\end{array}$ \\
\hline & EMISSÕES DE $\mathrm{CO}_{2}$ TOTAIS & $\mathrm{kg} / \mathrm{t}$ & 0,47 & 0,43 & 0,36 & 0,52 \\
\hline
\end{tabular}




\section{CONCLUSÃO}

É conveniente adotar estratégias de sustentabilidade para projetos atuais e futuros na indústria mineral e, com base nessa perspectiva, a etapa de cominuição deve ocupar um lugar de destaque entre as potenciais oportunidades de melhora. $\mathrm{O}$ fato de ter uma melhor compreensão da ferramenta de ACV e de sua aplicação contínua pode ser de importante utilidade para este propósito. Isto foi evidenciado por meio de um estudo de caso que permitiu encontrar a rota ótima de cominuição para um minério de ferro itabirítico dentre quatro possíveis alternativas, sendo a alternativa mais sustentável aquela correspondente a um circuito de cominuição que emprega HPGR com alimentação escalpada como estágio de britagem terciária, seguido por uma etapa de moagem em moinho de bolas. A maioria das rotas de processamento consideradas neste estudo de caso demonstraram que as emissões de $\mathrm{CO}_{2}$ foram aproximadamente iguais para ambas as energias direta e indireta. Esta constatação pode estar associada principalmente à ampla disponibilidade de fontes energéticas renováveis na matriz elétrica brasileira comparada com aquela dos países industrializados, o que demonstra a importância deste exercício no contexto particular de cada país.

\section{Agradecimentos}

Os autores agradecem às agências de financiamento CAPES, CNPq e FAPERJ pelo apoio a esta pesquisa.

\section{REFERÊNCIAS}

1 Alting, L. (2007). Life Cycle Engineering and Management: Status and Perspectives. In: G. Seliger (Ed.), Sustainability in Manufacturing - Recovery of Resources in Product and Material Cycles. Berlin, Germany: Springer-Verlag Berlin Heidelberg.

2 Laurence, D. (2011). Establishing a sustainable mining operation: an overview. Journal of Cleaner Production, 19, 278-284.

3 Tuazon, D., Corder, G., Powell, M., e Ziemski, M. (2012). A practical and rigorous approach for the integration of sustainability principles into the decision-making processes at minerals processing operations. Minerals Engineering, 29, 65-71.

4 Napier-Munn, T. (2015). Is progress in energy-efficient comminution doomed? Minerals Engineering, 73, 1-6.

5 McLellan, B. C., Corder, G. D., Giurco, D., e Green, S. (2009). Incorporating sustainable development in the design of mineral processing operations - Review and analysis of current approaches. Journal of Cleaner Production, v. 17, 1414-1425.

6 Batterham, R. (2014). Lessons in sustainability from the mining industry. Procedia Engineering, 83, 8-15.

7 Farrel, M. J. (2009). Carbon emissions from base metal mine sites. Acesso em 26 de janeiro de 2015, disponível em Mining Engineering: http://www.minecost.com/Carbon_Emissions_ME.pdf

8 World Bank. (2013). Mapping Carbon Pricing Initiatives: Developments and Prospects. Washington DC

9 Segura, J., e Tavares, L. M. (2014). Comparing comminution routes for a Brazilian iron ore using sustainability principles. Proceedings of XXVII International Mineral Processing Congress. Santiago.

10 Memary, R., Giurco, D., Mudd, G., e Mason, L. (2012). Life cycle assessment: a timeseries analysis of copper. Journal of Cleaner Production, 33, 97-108. 
11 McNab, B., Jankovic, A., David, D., e Payne, P. (2009). Processing of Magnetite Iron Ores - Comparing Grinding Options. Iron Ore Conference. Perth.

12 Pokrajcic, Z., O'Halloran, R., e Jones, C. (2010). Evaluation of Comminution Circuit Design for Sustainability Using ECONOMICS. XXV International Mineral Processing Congress (IMPC) Proceedings. Brisbane.

13 Norgate, T., e Jahanshahi, S. (2011). Reducing the greenhouse gas footprint of primary metal production: Where should the focus be? Minerals Engineering, v. 24, 1563-1570.

14 Henriques JR, M. (2010). Potencial de redução de emissão de gases de efeito estufa pelo uso de energia no setor industrial brasileiro. Tese de Doutorado, COPPE/UFRJ, Rio de Janeiro.

15 Rankin, J. (2012). Energy Use in Metal Production. High Temperature Processing Symposium. Swinburne University of Technology.

16 Instituto Aço Brasil. (2013). Relatório de Sustentabilidade 2013. Rio de Janeiro.

17 CNI/IAB. (2012). A indústria do aço no Brasil. Brasília.

18 Borba, B., Lucena, A., Rathmann, R., Costa, I., Nogueira, L., Rochedo, P., e Schaeffer, R. (2012). Energy-related climate change mitigation in Brazil: Potential, abatement costs and associated policies. Energy Policy, 49, 430-441.

19 Caldeira-Pires, A. (2010). Life Cycle Metodology and its application in Eco-labeling. Regional Workshop on Eco-Labeling for Latin American Countries. Rio de Janeiro.

20 Landfield, A. H., e Karra, V. (2000). Life cycle assessment of a rock crusher. Resources, Conservation and Recycling, v. 28, 207-217.

21 Musa, F., e Morrison, R. (2009). A more sustainable approach to assessing comminution efficiency. Minerals Engineering, v. 22, 593-601.

22 Segura, J. (2014). Comparação de rotas de cominuição de minério de ferro itabirítico usando conceitos de sustentabilidade e eficiência energética. Dissertação de Mestrado, COPPE/UFRJ, Rio de Janeiro. 